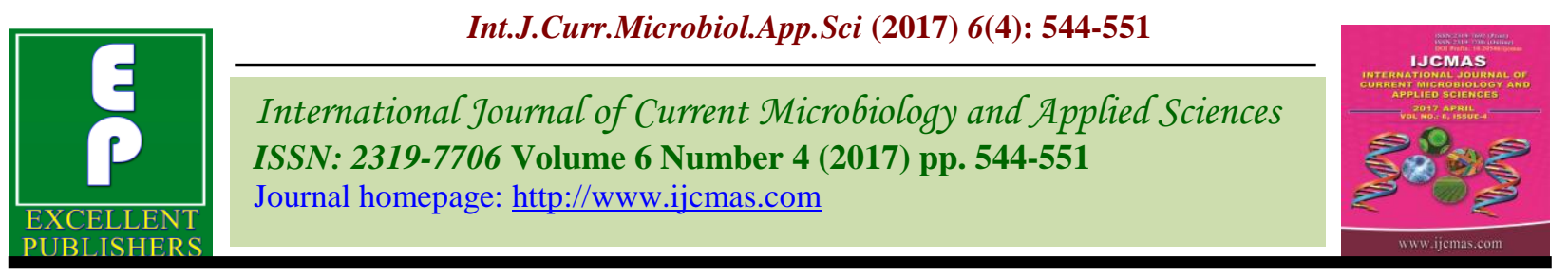

Original Research Article

https://doi.org/10.20546/ijcmas.2017.604.066

\title{
Isolation and Characterization of a Promising Plant Growth Promoting Rhizobacterium from Trichosanthes dioica Roxb. Rhizosphere
}

\author{
Satinath Das and Narayan C. Mandal* \\ Mycology and Plant Pathology Laboratory, Department of Botany, Visva-Bharati, \\ Santiniketan 731235, West Bengal, India \\ *Corresponding author
}

\begin{abstract}
A B S T R A C T
Keywords

PGPR, Anti fungal,

Scanning electron

microscopy,

Burkholderia.

Article Info

Accepted:

06 March 2017

Available Online:

10 April 2017

A total number of 10 rhizosperic bacteria were isolated from root environment of some healthy plants of a drastic diseased field with massive blighted symptoms of Trichosanthes dioica of Akilpur of Hooghly district, West Bengal $\left(22.94^{\circ} \mathrm{E} 88.12^{\circ} \mathrm{N}\right)$ where soil is alluvial in nature. Among the isolates, one strain TR9 showed remarkable plant growth promoting activity. Cell free culture filtrate of TR9 produced clear zones of inhibition (diameter ranging from $1.67 \mathrm{~cm}$ to $2.67 \mathrm{~cm}$ ) against different plant pathogenic fungi viz. Colletotrichum acutatum, Alternaria alternata and Helminthosporium compactum. It is quite capable of lowering the $\mathrm{pH}$ of its environment and also can solubilise insoluble phosphate sources. Siderophore production by this strain gives a positive result. Biochemical characterization indicated the ability of the strain to utilize a broad range of carbon sources, catalase positivity and also to reduce the nitrate and nitrite. It is highly sensitive to 4-quinolone derivative antibiotics viz. ciprofloxacin, norfloxacin and resistant to beta lactams like ampicilin, cephalothin, cephalexin. Light compound microscopy showed it to be a Gram negative rod shaped one which was re established by scanning electron microscopy. All these characteristic features indicate the strain to be a species of Burkholderia.
\end{abstract}

\section{Introduction}

Plants-microbes relationship is a common but important phenomenon. Diverse microorganisms, varying from pathogens to beneficial, continuously interact with higher plants in soil ecosystem and influence the development of plant growth in the soil (Ahmad et al., 2008; Taghavi et al., 2009). In the rhizosphere of crop plants it is crucial in contributing protection as well as supplementation of nutrients to the crop plants by their microbial associates. Among the different plant growth promoting characters, ability to solubilize insoluble phosphatic materials in the soil, production of siderophore for iron chelation, ability to kill pathogens to crop plants makes a rhizospheric bacterial strain more potent PGPR. Efficient insoluble phosphate solubilizing microorganisms have been isolated from various rhizosphere with PGP activity (Ghosh et al., 2016; Rodriguez and Fraga, 1999). Exploration by characterizing all those PGP activities may lead to find a promising PGPR strain for field application. As phytopathogens reduce crop productivity at various extents, control of such pathogens become 
necessary. Proper and tricky use of these rhizospheric bacteria can be a sharp wing of biological control. Many rhizobacteria are proven to be useful in inhibiting plant pathogens efficiently (Plant Pathology, Agrios, 2005; Ghosh et al., 2015; Ghosh et al., 2016). In our present endeavor we also wanted to isolate a potent PGPR strain from alluvial soil zone of lower Gangetic plain, where the soil is highly active because of elite agricultural practice and phosphate requirement in the soil is in highest demand.

\section{Materials and Methods}

\section{Isolation of the organism}

Rhizospheric soil of a very healthy Trichosanthes dioica plant from a heavily diseased field with massive blighted symptoms was collected from Akilpur of Hooghly district, West Bengal, India. The soil sample was quickly brought to laboratory. One gram of soil was mixed in $10 \mathrm{ml}$ of sterile distilled water very well to make a suspension. Different dilutions of the soil suspension were spread on Pikovskaya agar medium containing in soluble tri calcium phosphate as sole phosphate source. Plates were incubated at $28 \pm 2^{\circ} \mathrm{C}$ for $72-96 \mathrm{hrs}$ for the growth of the soil microbes. The composition of Pikovskaya agar medium was like $(\mathrm{gm} / \mathrm{L})$ : dextrose 10; $\mathrm{Ca}_{3} \mathrm{PO}_{4} \quad$ 5; $\left(\mathrm{NH}_{4}\right)_{2} \mathrm{SO}_{4} 0.5 ; \mathrm{NaCl} 0.2 ; \mathrm{MgSO}_{4} 0.1 ; \mathrm{KCl}$ 0.2 ; yeast extract $0.5 ; \mathrm{MnSO}_{4}, 7 \mathrm{H}_{2} \mathrm{O} 0.002$; $\mathrm{FeSO}_{4}, 7 \mathrm{H}_{2} \mathrm{O}$ 0.002; agar agar 20, $\mathrm{H}_{2} \mathrm{O} 1000$ $\mathrm{ml} ; \mathrm{pH}$ 7.0 \pm 0.2 . Bacterial colonies, forming clear solubilizing appearance round it on insoluble phosphate containing Pikovskaya agar plate, were selected, purified and maintained for further studies.

\section{Antifungal studies}

Antifungal activity of the selected strain TR9 strain was evaluated against three plant pathogenic fungi viz. Colletotrichum acutatum MTCC2074, Alternaria alternata VBAV007 and Helminthosporium compactum MTCC351 using cell free supernatant of TR9 by agar well diffusion (Fernández et al., 1992) method and dual culture over lay method (Magnusson and Schnürer, 2001).

Agar well diffusion method: The rhizospheric strain TR9 was cultured in nutrient broth at $28 \pm 2{ }^{\circ} \mathrm{C}$ and aliquots were collected at every $24 \mathrm{hrs}$ interval for five days. The aliquots were centrifuged to collect the supernatants, $50 \mu 1$ of which was further used in the wells on malt agar plates seeded with three fungal spores. The plates were incubated for next 72-96hrs and observed.

Dual culture overlay method: The bacterial strain was streaked on sterile nutrient agar medium plates and were allowed to grow for $24 \mathrm{hrs}$ at $28 \pm 2{ }^{\circ} \mathrm{C}$. Seven $\mathrm{ml}$ of malt extract soft agar $(0.7 \%$ agar $)$ medium containing $100 \mu 1$ of fungal mycelia culture were overlaid on the plates. Plates were further incubated for next 72-96 hrs at the same incubation condition.

\section{Phosphate solubilization}

TR9 was screened upon creation of prominent clear solubilizing zone on Pikovskaya agar plate. The quantitative assay of phosphate solubilization was performed using Pikovskaya broth with insoluble tri calcium phosphate as sole phosphate source. TR9 was inoculated to $100 \mathrm{ml}$ sterile Pikovskaya broth with $0.5 \%$ tri calcium phosphate $(\mathrm{w} / \mathrm{v})$ at $28 \pm 2^{\circ} \mathrm{C}$ with mild shaking condition (100rpm) for $120 \mathrm{hrs}$. After regular interval of $24 \mathrm{hrs}$ daily aliquots were collected. Uninoculated Pikovskaya broth was treated as control. The amount of soluble phosphate was measured by the method of Chen (Chen et al., 1956) after centrifuging the culture filtrate at 10000 rpm for 10 minutes. The experiment was performed in three sets separately. 


\section{Measurement of $\mathrm{pH}$}

The $\mathrm{pH}$ of the cultures was measured at different days of incubation in Pikovskya broth containing insoluble phosphate with the help of a digital $\mathrm{pH}$ meter (Systronics Digital $\mathrm{pH}$ meter 802). The experiment was performed with a triplet set.

\section{Siderophore production assay}

The qualitative test for production of siderophore by TR9 was performed on CAS (Chrome Azurol S) agar plate (Ames-Gottfred et al., 1989). Sterile CAS agar plates were prepared following protocol. The bacterial strain was streaked on the plates and incubated for $24-48 \mathrm{hrs}$ at $28 \pm 2^{\circ} \mathrm{C}$ to check if there is any orange coloration.

\section{Biochemical tests}

\section{Carbohydrate utilization test}

Carbohydrate utilization test was performed with HiCarbo ${ }^{\mathrm{TM}}$ kit (KB009A /KB009B1 / KB009C). TR9 was inoculated in nutrient broth and incubated overnight and checked the OD at $620 \mathrm{~nm}$ if it was more than 0.5. Uninoculated nutrient broth was set as control one. Culture with OD $\geq 0.5$ was taken and inoculated $50 \mu \mathrm{l}$ in each well of the kit. The kit (Part a, Part B and Part C) were incubated at $30 \pm 2^{\circ} \mathrm{C}$ for $18-24 \mathrm{hrs}$.

\section{Catalase test}

Catalase test was performed to take some amount of freshly cultured colonies on a clean dry glass slide with the help of a loop 1-2 drops of $3 \% \quad \mathrm{H}_{2} \mathrm{O}_{2}$ was added to it and checked if any bubble formation occurred.

\section{Nitrate reduction test}

Nitrate reduction test was done using ready prepared nitrate broth from HiMedia. The bacteria was inoculated into this broth and observed after incubation of $32 \pm 2^{\circ} \mathrm{C}$ for 18 $24 \mathrm{hrs}$.

\section{Antibiotic sensitivity assay}

Antibiotic sensitivity assay was performed using Himedia Octodiscs. From a freshly cultured medium, $100 \mu \mathrm{l}$ was taken and evenly spread over nutrient agar plates. Each of the seven octodiscs holding different antibiotics at different concentrations was placed on the plates. It was incubated at $28 \pm 2^{\circ} \mathrm{C}$ for $24 \mathrm{hrs}$.

\section{Scanning electron microscopic study}

Morphology study was performed via scanning electron microscopy. The specimen was prepared as follows: overnight cultured cells were harvested by centrifugation at $10000 \mathrm{rpm}$ for 10 minutes. Bacterial cell pellets were collected and washed twice saline and prefixed with a mixture of $3 \%$ gluteraldehyde and 5\% DMSO in $0.05 \mathrm{M}$ acetate buffer, $\mathrm{pH}$ 5.0, for 30 minutes. After centrifuging at $10000 \mathrm{rpm}$ for 10 minutes cell pellets were harvested and washed twice with $0.1 \mathrm{M}$ sodium acetate buffer, $\mathrm{pH}$ 5. Cells were collected centrifuging at $10000 \mathrm{rpm}$ for 10 minutes and applied over a thin slide, heat fixed and were dehydrated through a series of ethyl alcohol starting with $30 \%$ through 40 , $50,60,70,80,90,95 \%$ and finally with $100 \%$ with 10 minutes of dehydration in each grade (Mandal et al., 2013). Slide was mounted on stab and gold coated (Coater IB-2, Gike Engineering, Japan) before observing in microscope (HITACHI S-530, Japan).

\section{Results and Discussion}

\section{Isolation of a potent phosphate solubilizing bacteria}

There is a vast possibility to have some plant growth supporting agent from a healthy plant 
of a diseased field. Thus ten phosphate solubilizing bacteria were isolated from such a healthy Trichosanthes dioica rhizospheric soil. Among those isolates, one strain, TR9 was selected for further studies considering its remarkable phosphate solubilizing ability (Fig. 1).

\section{Characterization of the isolated strain}

The strain was characterized based on morphological and biochemical parameters. For morphological characterization Gram staining and SEM study was done. Gram staining revealed the strain to be Gram negative rod shaped which was supported by the SEM study (Fig. 2) also. The strain responded positively to nitrate and catalase tests. TR9 can utilize dextrose, maltose, fructose, mannose and showed positive response for esculin hydrolysis, citrate utilization and malonate utilization (Table 1). The strain was resistant to beta lactum antibiotics like ampicilin, cephalothin, cephalexin but sensitive to tetracycline, kanamycin, streptomycin, chloramphenicol, norfloxacin, gentamycin, tobramycin, trimethoprim and others (Table 2). Based on the different biochemical and morphological characteristics and matching the data obtained with Bergeys' Manual of Systematic Bacteriology (Vermis et al., 2002) the strain was preliminary identified to be a member of the genus Burkholderia.

Table.1 Different carbohydrate utilization by TR9

\begin{tabular}{|l|c|l|c|}
\hline Carbohydrates & Utilization by TR9 & Carbohydrates & Utilization by TR9 \\
\hline Lactose & + & L-Arabinose & + \\
\hline Xylose & + & Mannose & + \\
\hline Maltose & + & Rhamnose & + \\
\hline Fructose & + & Cellobiose & + \\
\hline Galactose & + & Sorbitol & + \\
\hline Dextrose & + & Citrate utilization & + \\
\hline Sucrose & + & Malonate utilization & + \\
\hline ONPG '+' indicates utilized, ‘-' not utilized & Esculin hydrolysis &
\end{tabular}

Figure.1 Phosphate solubilization by TR9




Table.2 Antibiotic sensitivity profile of TR9

\begin{tabular}{|l|l|l|l|l|l|}
\hline \multicolumn{1}{|c|}{$\begin{array}{c}\text { Antimicrobial } \\
\text { agent }\end{array}$} & Sensitivity & $\begin{array}{c}\text { Antimicrobial } \\
\text { agent }\end{array}$ & Sensitivity & $\begin{array}{c}\text { Antimicrobial } \\
\text { agent }\end{array}$ & Sensitivity \\
\hline Tetraclycine & Sensitive & Gentamycin & Sensitive & Penicillin-G & Resistant \\
\hline Amikacin & Sensitive & Norfloxacin & Sensitive & Ampicilin & Resistant \\
\hline Carbenicilin & Sensitive & Tobramycin & Sensitive & Cephalothin & Resistant \\
\hline Ciprofloxacin & Sensitive & Clindamycin & Resistant & Colistin & Resistant \\
\hline Co-Trimazine & Sensitive & Vancomycin & Sensitive & Sulphatriad & Sensitive \\
\hline Kanamycin & Sensitive & Cloxacilin & Resistant & Ticarcilin & Sensitive \\
\hline Nitrofurantoin & Resistant & Cefaloridine & Sensitive & Cefalexin & Resistant \\
\hline Streptomycin & Resistant & Linkomycin & Resistant & Erythromycin & Resistant \\
\hline Chloramphenicol & Sensitive & Methicilin & Resistant & Oxacilin & Sensitive \\
\hline Sulphamethoxazole & Resistant & Oleadomycin & Sensitive & Amoxicilin & Resistant \\
\hline
\end{tabular}

Table.3 Anti fungal activity of TR9 by dual culture overlay method

\begin{tabular}{|c|c|c|c|c|c|}
\hline \multirow{2}{*}{$\begin{array}{l}\text { Plant pathogenic } \\
\text { fungal strains }\end{array}$} & \multicolumn{5}{|c|}{ Diameter of zones of inhibition $(\mathrm{cm})$} \\
\hline & $\begin{array}{c}\text { Day } \\
1\end{array}$ & Day 2 & Day 3 & Day 4 & Day 5 \\
\hline $\begin{array}{l}\text { Colletotrichum } \\
\text { acutatum MTCC } 2074\end{array}$ & 1.27 & 1.38 & 1.7 & 1.96 & 2.67 \\
\hline $\begin{array}{l}\text { Alternaria alternata } \\
\text { VBAV007 }\end{array}$ & 1.58 & 1.6 & 1.62 & 1.66 & 1.67 \\
\hline $\begin{array}{l}\text { Helminthosporium } \\
\text { compactum MTCC } 351\end{array}$ & 1.9 & 1.97 & 1.98 & 2.0 & 2.47 \\
\hline
\end{tabular}

Figure.2 Scanning electron micrograph of TR9

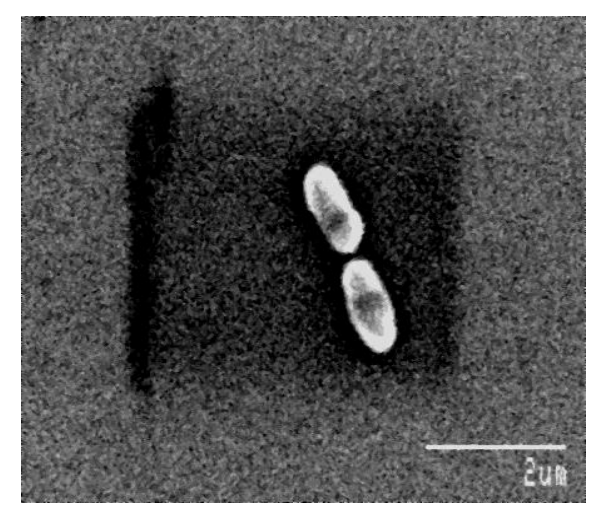


Figure.3 Antifungal activity of TR9 by dual culture overlay method against A) Colletotrichum acutatum MTCC2074 B) Alternaria alternata VBAV007
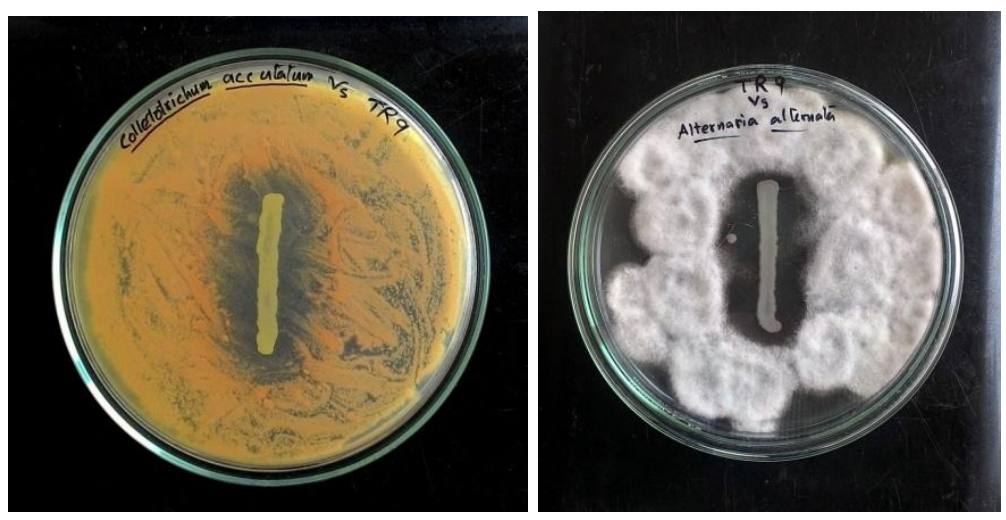

Figure.4 Phosphate solubilizing kinetics with $\mathrm{pH}$ drops by TR9

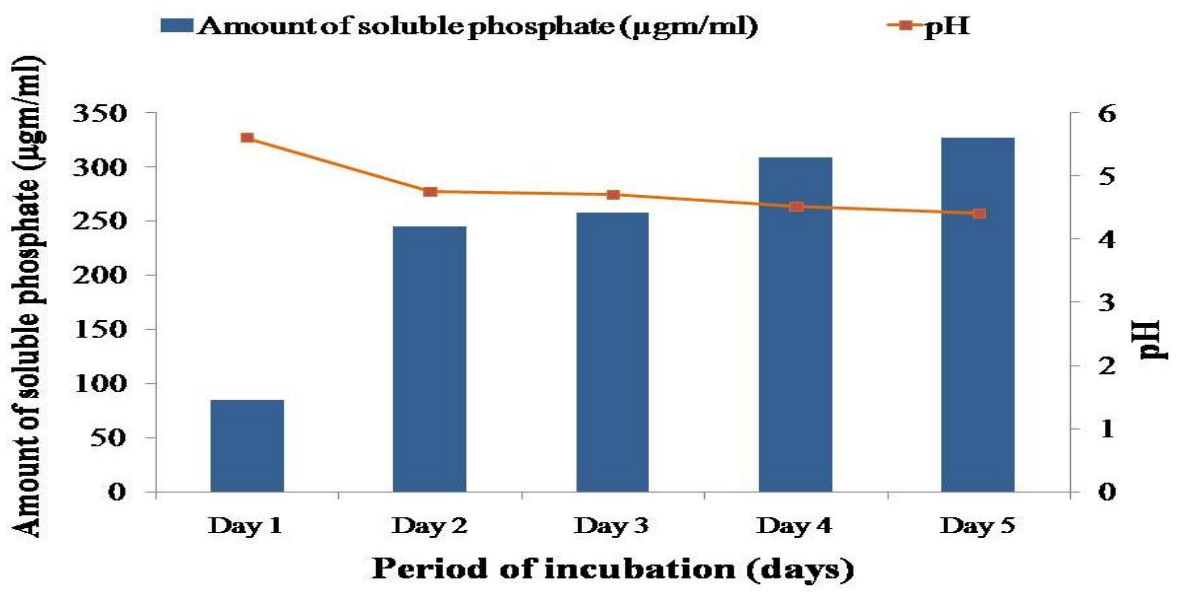

Figure.5 Siderophore production by TR9

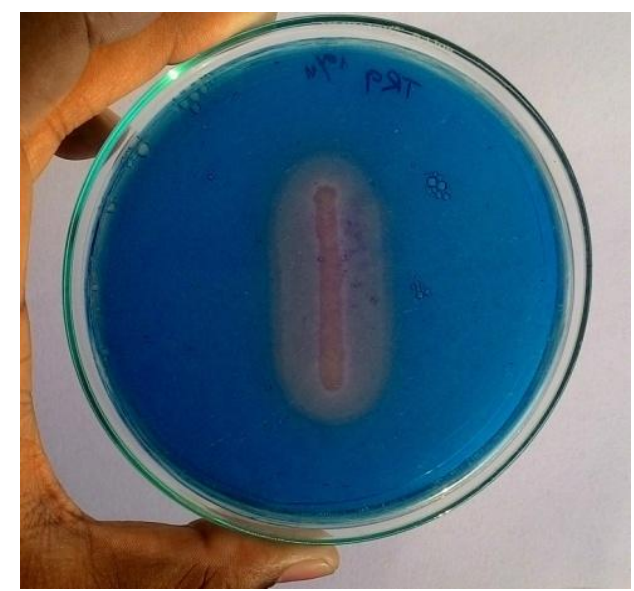




\section{Antifungal activity of the strain}

TR9 showed a clear antagonistic activity against Colletotrichum acutatum, Alternaria alternata and Helminthosporium compactum when tested via dual culture overlay method (Fig. 3) against different plant pathogenic fungi. It produced a very clear zone of inhibition suppressing the fungal growth surrounding it. The results obtained are very promising in terms of biological control of phytopathogens. In agar well diffusion method increasing of diameter of zones of inhibition found with $5^{\text {th }}$ day of culture filtrate.

Maximum inhibition was found in case of Helminthosporium compactum when it was treated with $5^{\text {th }}$ day culture of TR9 where the diameter of zone of inhibition was $2.67 \mathrm{~cm}$. On the other hand least inhibition by the strain was found for $5^{\text {th }}$ day CFS against Alternaria alternata which was $1.66 \mathrm{~cm}$. Day wise antifungal data is tabulated in table 3 . It is previously reported that Burkholderia cenocepacia can successfully control the leaf spot of Aloe vera caused by Alternaria alternata (Ghosh et al., 2016)and also can reduce the incidence of fruit rot of jackfruit by Rhizopus stolonifer (Ghosh et al., 2015). Not only from the view of PGP activities, TR9 can be helpful in disease control too.

\section{Kinetics of phosphate solubilization and siderophore production}

The strain is quite capable to solubilize insoluble phosphate of Pikovskaya broth containing insoluble tricalcium phosphate and produced $327 \mu \mathrm{g} / \mathrm{ml}$ soluble $\mathrm{P}$ at 5 th day of incubation while $\mathrm{pH}$ of the culture drops to 4.41. A rapid increase of amount soluble phosphate was found in between 24 to $48 \mathrm{hrs}$ which is $85 \mu \mathrm{g} / \mathrm{ml}$ to $245 \mu \mathrm{g} / \mathrm{ml}$ and it is also reflected in lowering the $\mathrm{pH}$ from 5.6 to 4.75 (Fig. 4). Solubilization of phosphate may be due to the production of organic acids like gluconic and 2-ketogluconic acids which chelates the metal cations from insoluble phosphates (Khan et al., 2009). This supports the gradual decrease of $\mathrm{pH}$. Formation of a clear bright orange coloration on blue CAS agar plate surrounding the growth of the bacteria indicates the ability of siderophore production by the strain (Fig. 5). As availability of ferric iron is crucial to proper functioning of the terminal oxidation pathway and ultimately the efficiency of the rhizobacteria, siderophore production by the selected strain TR9 thus makes it an efficient one.

In conclusion microbiology and agriculture are very tightly connected to each other. From the root tip to the top of shoot or from the view of pathogen to bio-control agent presence of microbes flash everywhere. Having some bacterial strain with different anti pathogenic property and plant growth promoting activity is a good sign from beneficial aspects. The strain TR9 which has been isolated from the Trichosanthes dioica rhizosphere has shown both nutrient mobilizing property as well as pathogen killing property which can be prospective biofertilizer inoculums in agricultural application after designing proper formulation.

\section{Acknowledgements}

$\mathrm{SD}$ is thankful to UGC for providing BSR fellowship

\section{References}

Agrios, G.N. 2005. Plant Pathol., (Elsevier, Academic Press) Fifth Edition.

Ahmad, F., Ahmad, I., and Khan, M.S. 2008. Screening of free-living rhizosphere bacteria for their multiple plant growth promoting activities, Microbiol. Res., 163: 173-181.

Ames-Gottfred, N.P., Christie, B.R., and Jordan, 
D.C. 1989. Use of the Chrome Azurol S agar plate technique to differentiate strains and field isolates of Rhizobium leguminosarum biovar trifolii. Appl. Environ. Microbiol., 55(3): 707-710.

Chen, P.S., Tonbara, T.Y., and Warner, H. 1956. Micro determination of phosphorus. Anal. Chem., 28: 1756-1758.

Fernández -Garayzábal, J.F., Delgado, C., Blanco, M., Vázquez-Boland, J.A., Briones, V., Suárez, G., Domínguez, L. 1999. Role of potassium tellurite and brain heart infusion in expression of the haemolytic phenotype of Listeria spp. on agar plates. Appl. Environ. Microbiol., 58: 434-438.

Ghosh, R., Barman, S., Khatun, J., and Mandal, N.C. 2016. Biological control of Alternaria alternata causing leaf spot disease of Aloe vera using two strains of rhizobacteria. Biol. Control, 97: 102-108.

Ghosh, R., Barman, S., Mukherjee, R., and Mandal, N.C. 2016. Role of phosphate solubilizing Burkholderia spp. for successful colonization and growth promotion of Lycopodium cernuum L.(Lycopodiaceae) in lateritic belt of Birbhum district of West Bengal, India. Microbiol. Res., 183: 80-91.

Ghosh, R., Barman, S., Mukhopadhyay, A., and Mandal, N.C. 2015. Biological control of fruit-rot of jackfruit by rhizobacteria and food grade lactic acid bacteria. Biol. Control, 83: 29-36

Khan, A.K., Jilani, G., Akhtar, M.S., Naqvi,
S.M.S. and Rasheed, M. 2009. Phosphorus solubilizing bacteria: occurrence, mechanisms and their role in crop production. J. Agric. Biol. Sci., 1(1): 48-58.

Magnusson, J., and Schnürer, J. 2001. Lactobacillus coryniformis subsp. Coryniformis strain SI3 produces a broadspectrum proteinaceous antifungal compound. Appl. Environ. Microbiol., 67: $1-5$.

Mandal, V., Sen, S.K., and Mandal, N.C. 2013. Production and partial characterization of an inducer dependent novel antifungal compound(s) by Pediococcus acidilactici LAB5. J. Sci. Food Agric., 93: 2445-2453.

Rodriguez, H., and Fraga, R. 1999. Phosphate solubilizing bacteria and their role in plant growth promotion, Biotechnol. Adv., 17: 319-339.

Taghavi, S., Garafola, C., Monchy. S., Newman, L., Hoffman, A., Weyens, N., Barac, T., Vangronsveld, J., and van der Lelie, D. 2009. Genome survey and characterization of endophytic bacteria exhibiting a beneficial effect on growth and development of poplar trees, Appl. Environ. Microbiol., 75: 748-757.

Vermis, K., Coenye, T., Mahenthiralingam, E., Nelis, J.H. and Vandamme, P. 2002. Evaluation of species specific recA-based PCR tests for genomover level identification within the Burkholderia cenocepacia complex. J. Med. Microbiol., 51: 937-940.

\section{How to cite this article:}

Satinath Das and Narayan C. Mandal. 2017. Isolation and Characterization of a Promising Plant Growth Promoting Rhizobacterium from Trichosanthes dioica Roxb. Rhizosphere. Int.J.Curr.Microbiol.App.Sci. 6(4): 544-551. doi: https://doi.org/10.20546/ijcmas.2017.604.066 